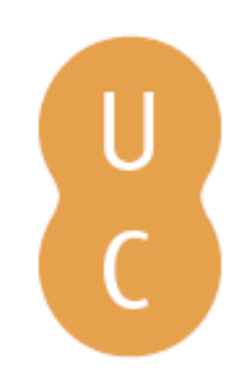

\title{
pombalina
}

\section{Avaliação do risco de tsunami nos municípios de Peniche e Lourinhã}

\author{
Autor(es): $\quad$ Santos, Ângela; Pereira, Susana; Fonseca, Nuno; Paixão, Raquel; \\ Andrade, Filomena
}

Publicado por: Imprensa da Universidade de Coimbra

URL

persistente: URI:http://hdl.handle.net/10316.2/38294

DOI: $\quad$ DOI:http://dx.doi.org/10.14195/9789892610993_10

Accessed : $\quad$ 26-Apr-2023 15:05:08

A navegação consulta e descarregamento dos títulos inseridos nas Bibliotecas Digitais UC Digitalis, UC Pombalina e UC Impactum, pressupõem a aceitação plena e sem reservas dos Termos e Condições de Uso destas Bibliotecas Digitais, disponíveis em https://digitalis.uc.pt/pt-pt/termos.

Conforme exposto nos referidos Termos e Condições de Uso, o descarregamento de títulos de acesso restrito requer uma licença válida de autorização devendo o utilizador aceder ao(s) documento(s) a partir de um endereço de IP da instituição detentora da supramencionada licença.

Ao utilizador é apenas permitido o descarregamento para uso pessoal, pelo que o emprego do(s) título(s) descarregado(s) para outro fim, designadamente comercial, carece de autorização do respetivo autor ou editor da obra.

Na medida em que todas as obras da UC Digitalis se encontram protegidas pelo Código do Direito de Autor e Direitos Conexos e demais legislação aplicável, toda a cópia, parcial ou total, deste documento, nos casos em que é legalmente admitida, deverá conter ou fazer-se acompanhar por este aviso.

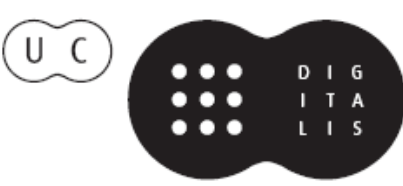




\section{TERRAMOTO DE \\ LISBOA DE 1755}

\section{O QUE APRENDEMOS \\ 260 ANOS DEPOIS?}

LUCIANO LOURENÇO

ÂNGELA SANTOS

(COORDS.)

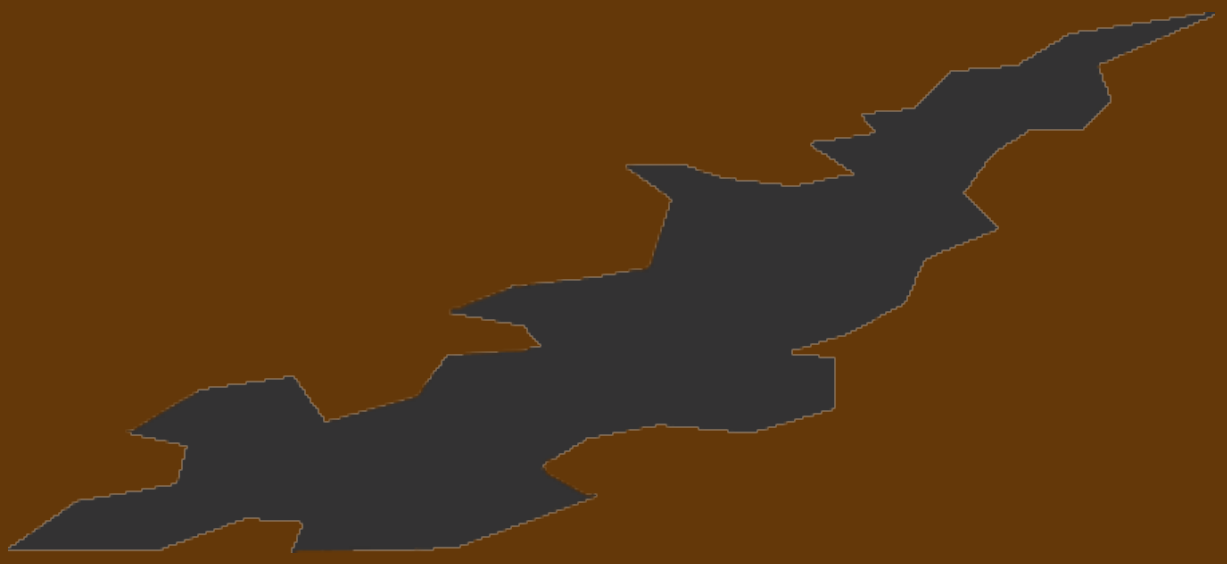

IMPRENSA DA UNIVERSIDADE

DE COIMBRA

COIMBRA

UNIVERSITY

PRESS 


\title{
AVALIAÇÁO DO RISCO DE TSUNAMI NOS MUNICÍPIOS DE PENICHE E LOURINHÃ
}

\section{TSUNAMI RISK ASSESSMENT AT PENICHE AND LOURINHÁ MUNICIPALITIES}

\author{
Ângela Santos \\ Centro de Estudos Geográficos, IGOT, Universidade de Lisboa \\ angela.santos@campus.ul.pt \\ Susana Pereira \\ Centro de Estudos Geográficos, IGOT, Universidade de Lisboa \\ susana.pereira@campus.ul.pt \\ Nuno Fonseca \\ Centro de Estudos Geográficos, IGOT, Universidade de Lisboa \\ nfonseca@campus.ul.pt \\ Raquel Paixão \\ Centro de Estudos Geográficos, IGOT, Universidade de Lisboa \\ raquelpaixao@campus.ul.pt \\ Filomena Andrade \\ CEHR-UCP, Universidade Aberta \\ fandrade@uab.pt
}

Sumário: Os relatos históricos do Tsunami de Lisboa de 1755 são compilados e validados por trabalho de campo e modelaçáo numérica de tsunami. Seguidamente, o modelo numérico é usado para o cálculo das áreas inundadas nos municípios de Peniche e Lourinhã. Avalia-se a perigosidade de tsunami nas áreas inundadas, sendo cruzada com os elementos expostos. Os resultados demonstram que no caso de ocorrência de um evento com as mesmas características do de 1755 , em Peniche a população presente exposta contabiliza 4671 pessoas e há 3124 edifícios que podem ser inundados, enquanto na Lourinhã há 956 residentes, e 68 edifícios em risco.

Palavras-chave: Tsunami de Lisboa de 1755, modelação numérica, trabalho de campo, perigosidade, risco 
Abstract: The historical accounts of the 1755 Lisbon Tsunami were compiled and validated by field survey and tsunami numerical modeling. Then, the numerical model is used to calculate the inundated areas on Peniche and Lourinhã municipalities. A criterion for tsunami hazard assessment is applied to the above inundated areas, being crossed with the exposed elements. The results show that a tsunami similar to the one occurred in 1755, Peniche would have 4671 people exposed and 3124 buildings would be inundated, while at Lourinhã there would be 956 residents at risk and 68 buildings that could be inundated.

Keywords: 1755 Lisbon Tsunami, numerical model, field survey, hazard, risk

\section{Introdução}

Os relatos históricos do sismo e tsunami de 1 de Novembro de 1755 são vastos e bastante completos, tendo sido analisados por vários autores (ex. A. Santos et al., 2009; A. Santos e S. Koshimura, 2015). Este evento histórico foi o maior desastre natural ocorrido em Portugal, com uma estimativa de mais de 12000 vítimas mortais (A. Santos e S. Koshimura, 2015) devido aos efeitos combinados do sismo, incêndios urbanos (em Lisboa e Setúbal) e tsunami.

A modelação numérica é uma ferramenta útil para validação dos relatos históricos do Tsunami de Lisboa de 1755 bem como a análise do impacto de um cenário semelhante ao ocorrido nessa altura. A sismotectónica ao largo de Portugal é complexa (A. Santos et al., 2009), sendo o Banco de Gorringe a maior estrutura batimétrica. Esta tem sido indicada como a origem mais provável do Tsunami de Lisboa de 1755, através da análise de relatos históricos combinada com a modelação numérica de tsunami à escala regional (A. Santos et al., 2009). Mais recentemente, a fonte (tsunami source model) foi validada à escala local, tendo sido realizada a modelação numérica em vários municípios, nomeadamente na Figueira da Foz (A. Santos et al., 2012) e em Setúbal (A. Santos e S. Koshimura, 2013; A. Santos et al., 2014). 
O objetivo deste estudo consistiu em avaliar o risco de tsunami nos municípios de Peniche e Lourinhá, Portugal (fig. 1), considerando o Tsunami de Lisboa de 1755 como o pior cenário possível. Para tal, em primeiro lugar procedeu-se à validação dos relatos históricos em Peniche e na freguesia de A-dos-Cunhados (concelho de Torres Vedras), com base em pesquisa dos relatos originais do tsunami, no trabalho de campo e na modelação numérica de tsunami. Seguidamente calcularam-se as áreas inundadas pelo tsunami nos referidos municípios e avalia-se a perigosidade de tsunami, com base nos tempos de percurso e alturas da inundação. Finalmente, identificaram-se e quantificaram-se os elementos expostos nas áreas inundáveis.

\section{Relatos históricos e trabalho de campo}

Os relatos históricos do Tsunami de Lisboa de 1755 em Portugal são bastante completos, tendo sido analisados (A. Santos e S. Koshimura, 2015) através da interpretação dos relatos históricos originais. O resumo dos parâmetros
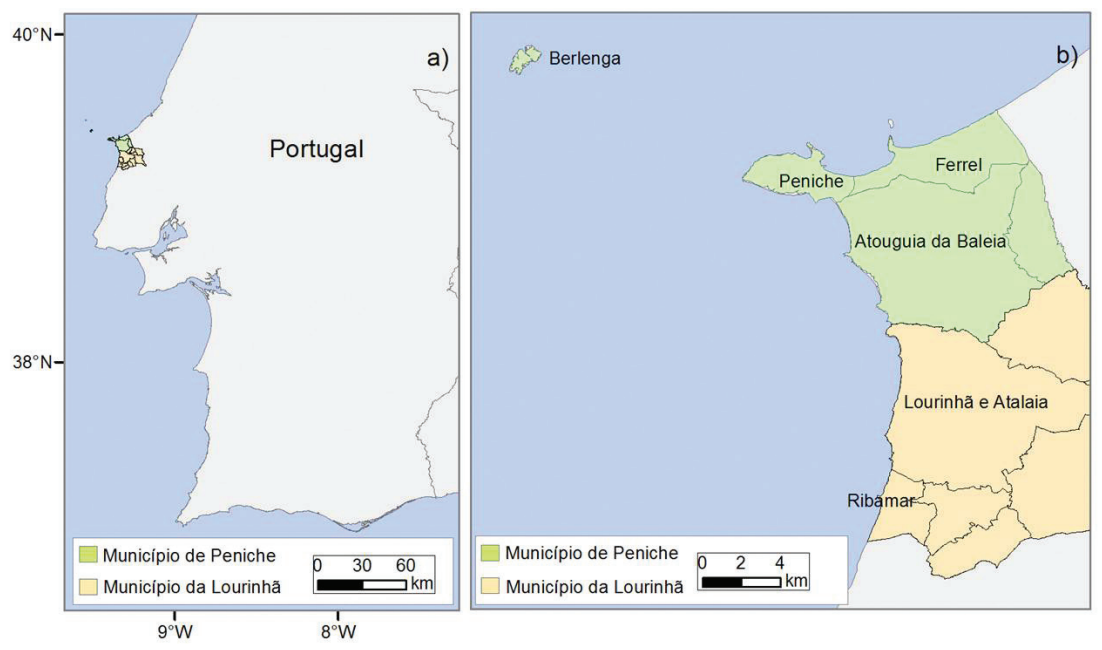

Fig. 1 - Enquadramento da área de estudo: a) localização dos municípios de Peniche e Lourinhã; b) Freguesias costeiras de Peniche e Lourinhã.

Fig. 1 - Framework of the study area: a) Location of Peniche and Lourinhã municipalities; b) Coastal Civil parishes of Peniche and Lourinhã. 
físicos do tsunami, dos estragos e número de vítimas mortais em Peniche e na freguesia de A-dos-Cunhados sáo apresentados na TABela I. Foi realizado trabalho de campo em Peniche e A-dos-Cunhados, em ocasióes diferentes em 2012: 6 Fevereiro, 21 e 22 de Agosto, 2, 29 e 30 de Dezembro. O objetivo do trabalho de campo foi validar os relatos históricos através do uso de GPS. O resumo dos resultados do trabalho de campo é apresentado na TABELA II, e a localização dos pontos está representada na fig. 2.

TABELA I - Resumo do impacto do Tsunami de Lisboa de 1755; (1) nas arribas (Fonte: A. Santos e S. Koshimura, 2015).

TABLE I - Summary of the 1755 Lisbon Tsunami's impact; (1) at the cliffs (Source: A. Santos and S. Koshimura, 2015).

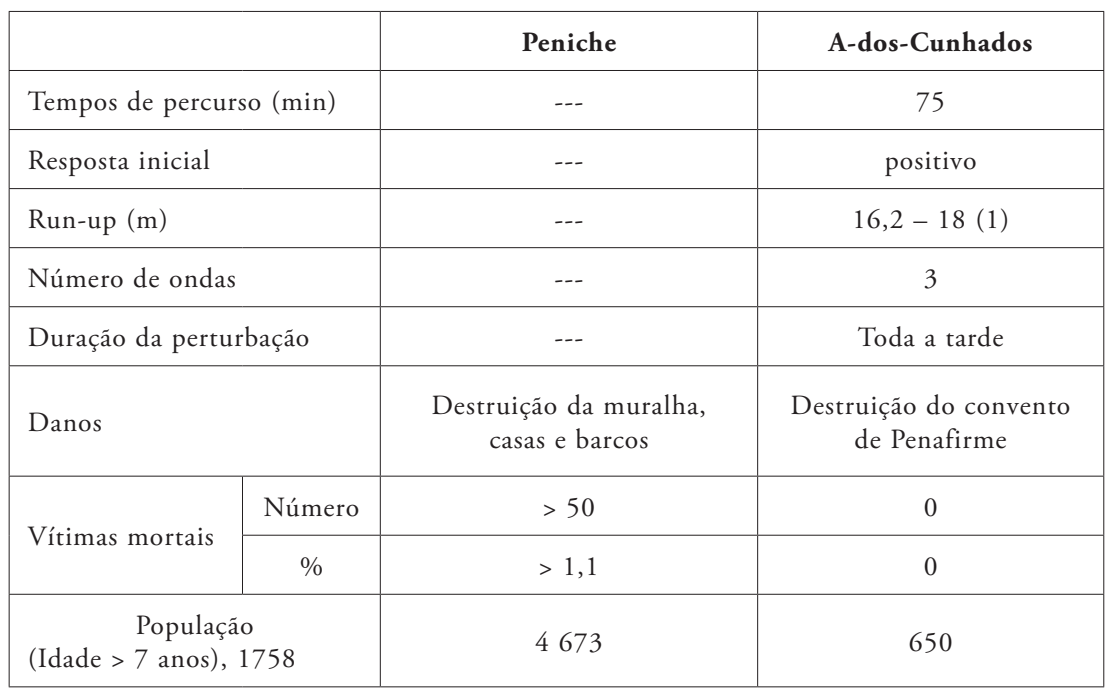

Os relatos do Tsunami de Lisboa de 1755 em Peniche são escassos, indicando que o tsunami destruiu a muralha, casas e barcos, provocando mais de 50 vítimas mortais, não tendo sido encontrado nenhum outro documento que possa complementar a TABELA I. Esta descriçáo corresponde à zona histórica (Ponto 1, da Tabela II e fig. 2) que ainda existe hoje. No entanto, o território municipal integra ainda o sistema dunar de Peniche que constitui uma vasta área de acumulação de sedimentos herdados do Holocénico (J.C. França et al., 
1960). Trata-se de um troço litoral baixo e arenoso marginado por imponentes relevos constituídos por rochas jurássicas, calcários e arenitos com cerca de 70 milhóes de anos (J.C. França et al., 1960), talhadas em arriba - os promontórios rochosos de Peniche, do Baleal e da Consolação - que atingem até $30 \mathrm{~m}$ de altitude. Apresenta praias estreitas (com largura $\leq 80 \mathrm{~m}$ ), em forma de arco, que se estendem quer a norte quer a sul por cerca de $3,5 \mathrm{~km}$. A largura do sistema dunar é variável, atingindo, a norte, até $500 \mathrm{~m}$, e a sul, cerca de $800 \mathrm{~m}$. Prolonga-se para o interior da plataforma litoral, evidenciando uma topografia moldada por algumas cristas e depressóes interdunares, raras vezes ultrapassando $15 \mathrm{~m}$ de altitude.

TABELA II - Resultados do trabalho de campo.

TABLE II - Field survey results.

\begin{tabular}{|l|c|c|c|}
\hline & $\begin{array}{c}\text { Longitude } \\
(\mathbf{(} \mathbf{W})\end{array}$ & $\begin{array}{c}\text { Latitude } \\
(\mathbf{o})\end{array}$ & $\begin{array}{c}\text { Cota } \\
(\mathbf{m})\end{array}$ \\
\hline 1. Peniche, zona histórica & 9,37885 & 39,35387 & 4,98 \\
\hline 2. Praia Porto Novo & 9,35504 & 39,17758 & 7,04 \\
\hline 3. Praia Porto Novo, ponto 2 & 9,356813 & 39,174670 & 17,43 \\
\hline 4. Praia Santa Rita & 9,356176 & 39,173863 & 7,04 \\
\hline 5. Termas dos Frades ou "Olhos de Água" & 9,337848 & 39,174508 & 5,01 \\
\hline 6. Maceira & 9,328006 & 39,182824 & 32,12 \\
\hline 7A. Termas do Vimeiro - piscinas & 9,325752 & 39,181274 & 8,38 \\
\hline 7B. Termas do Vimeiro - Águas Santas & 9,325523 & 39,181276 & 8,28 \\
\hline CPR. Casal Porto Rio & --- & --- & --- \\
\hline QP. Quinta da Piedade & --- & -- & -- \\
\hline 8A. Ruinas do Convento de Penafirme - entrada & 9,355426 & 39,163392 & 13,52 \\
\hline 8B. Ruinas do Convento de Penafirme - estrada & 9,355335 & 39,163560 & 15,44 \\
\hline 9. Costa da Póvoa de Penafirme - Praia de Santa & 9,376074 & 39,142129 & 30,79 \\
\hline Cruz & 9,359082 & 39,145423 & 69,86 \\
\hline 10. Póvoa de Penafirme & 9,354436 & 39,144532 & 70,36 \\
\hline 11. Convento de Penafirme & 9,300535 & 39,152481 & 15,14 \\
\hline 12. Igreja de A-dos-Cunhados & & \\
\hline
\end{tabular}


O sistema dunar evidência atualmente, indícios de degradação geomorfológica da duna frontal, induzidos por erosáo marinha e pisoteio antrópico, o que condiciona em grande medida a sua capacidade de resiliência e vulnerabilidade biofísica (R. Paixão, 2011, 2013).

Este troço litoral sofreu um processo secular de evolução geomorfológica (fig. 2), tendo ficado definitivamente prefigurado no século XVI, quando a ilha de Peniche perden a sua insularidade (M.L.P. Blot, 2003), embora J.A. Dias (2009) relate que ainda no século XVII, aquando da preia-mar viva, o mar cobria as acumulaçôes sedimentares. Assim, a 1 de Novembro de 1755 a configuração deste troço litoral seria aproximada às características geomorfológicas atuais, considerando-se legítima a hipótese de utilizar a topografia atual na modelação numérica de tsunami para validar os relatos históricos.

Por outro lado, os relatos históricos na freguesia de A-dos-Cunhados (na atualidade dividida entre as freguesias de A-dos-Cunhados e Maceira, pertencentes ao município de Torres Vedras) indicam que o tsunami chegou a A-dos-Cunhados 75 minutos após o sismo atingindo mais de $16 \mathrm{~m}$ de altura

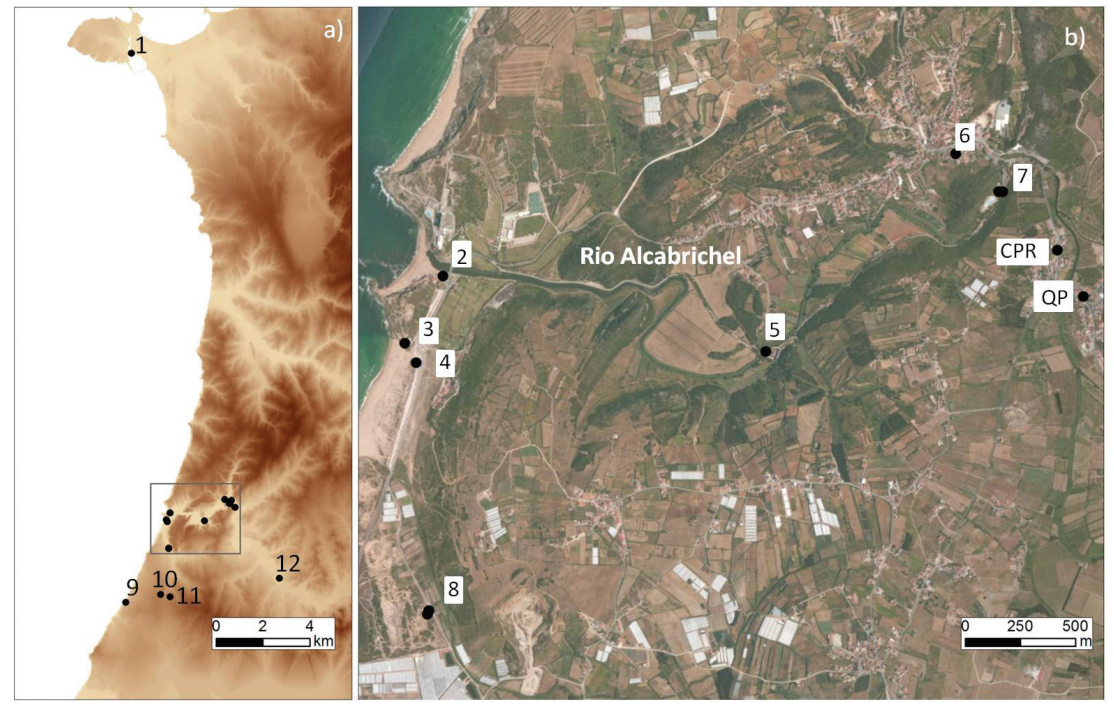

Fig. 2 - Locais descritos pelas testemunhas, onde o trabalho de campo foi realizado.

Fig. 2 - Places described by the eyewitnesses, where the field survey was conducted. 
nas arribas da praia do Porto Novo (TABela I). As testemunhas mencionaram ainda que ocorreram três grandes ondas, as quais, apesar de não terrem provocado vítimas, destruíram o convento de Penafirme.

De facto, os relatos coevos são muito completos e fornecem uma análise ainda mais detalhada à escala local do que a apresentada na TABELA I. Um dos documentos originais data de Maio de 1756, em que o Padre José Fialho, da Igreja de A-dos-Cunhados, o copiou integralmente à mão chamando-lhe “Algumas notas curiosas" (J. Fialho, 1910); a cópia original de 1910 possivelmente já não existe, mas a fotocópia deste documento ainda se encontra nos arquivos da igreja de A-dos-Cunhados, com oito páginas. Este documento tem sido novamente copiado na íntegra por vários autores, tendo a vantagem de estas réplicas já estarem escritas com letra de imprensa, o que facilita a interpretação (L. Sousa, 1928; J. Camilo; 1998, J. Fontes, 2002). No entanto, as testemunhas relatam o tsunami utilizando unidades de medida Históricas Portuguesas, pelo que neste estudo considerou-se a seguinte conversão: 1 légua $=4500 \mathrm{~m}$ (A. Oliveira, 1985).

Diz o documento: "(...) A novidade que se vio [sic] no mar nas partes da Povoa e Porto-Novo de Penafirme, que são os limites desta freguezia [sic] que confinão [sic] com o mar, foi levantar-se alto, coiza [sic] de meia légua [2250 m] distante da terra em hum [sic] grande monte (...) chegando pela terra dentro a distancia de que não há tradição chegasse em tempo algum; (...) recolhendo as águas com tanta velocidade que ficava tudo enxuto até à distância em que se tinha levantado (...). A terra não abriu bocas em que houvesse submersão [sic]. Abriu sim fendas em muitas partes e rebentarão [sic] sim muitas fontes e olhos de agua [sic] e em alguns se notou algum mau cheiro que propendia a enxofre (...) muitos que rebentarão [sic] nas varzeas [sic] desta freguezia [sic] que medeia entre os casais do Porto Rio e Quinta da Piedade (...) ficando este sitio meia légua [2250 m] distante do mar e rebentaram os tais [olhos de água] trazendo areia branca (...) e outra ao modo de cinza. (...) Cunhados 24 de Maio de 1756 - O Cura Antonio Duarte”.

Um outro registo do tsunami na freguesia de A-dos-Cunhados foi incluído nos Censos de 1758 reproduzido por J. Fontes (2002): “(...) Não he [sic] muralha nem tem castello, ou torre antigua [sic]; tem somente o forte do Porto Novo, 
que tem seu Cabo, ou Capitão com seus soldados e que nelle [sic] fazem suas sentinelas. Porem o tal so existe no nome porque se acha arruinado, e em muita parte demolido. (...) o convento de Pena Firme ficou inabitável e hum [sic] novo que os Religiosos edificarão [sic] junto do lugar da Povoa onde fizeram um Hospicio [sic] em que morão [sic] ficou tão arruinado que é preciso tornar dos fundamentos no que já se trobalha [sic] (...)”.

Um terceiro documento relata, segundo J. Fontes (2002) que "a guarnição do forte do Porto Novo salvou-se tendo-se recolhido numa casa levantada no monte da vigia e as cinco peças de artilharia ficaram encravadas nas rochas."

$\mathrm{Na}$ freguesia de A-dos-Cunhados, o antigo convento de Penafirme, que data do séc. XVI, estava inicialmente localizado mais perto da costa. Antes de 1535 não
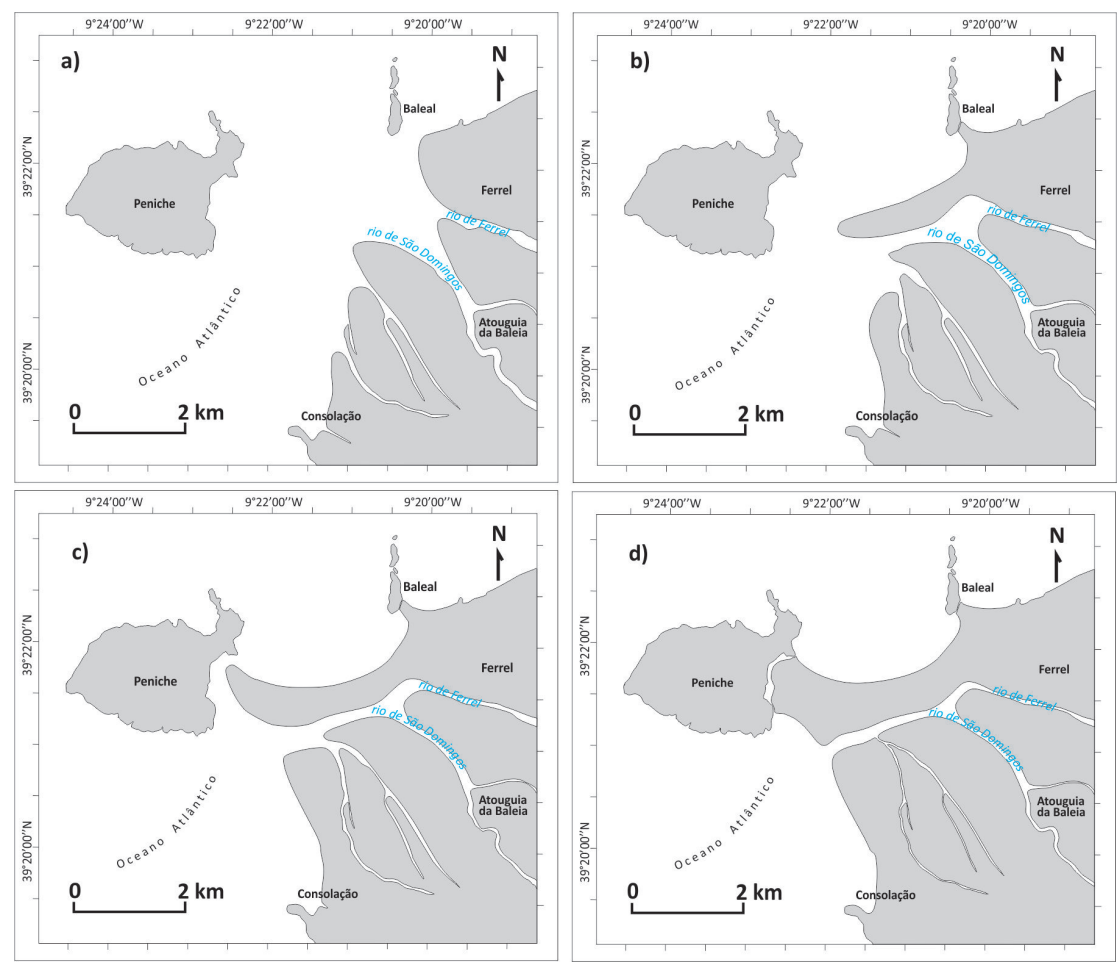

Fig. 3 - Evolução do assoreamento em Peniche: séculos a) XII, b) XIV, c) XV, d) XVI (Fonte: R. Paixão, 2011, adaptado de M.L.P. Blot, 2003).

Fig. 3 - Coastline evolution in Peniche: a) XII, b) XIV, c) XV, d) XVI centuries (Source: R. Paixão, 2011, adapted from M.L.P. Blot, 2003). 
existe praticamente nenhuma documentação refente ao convento, no entanto a partir dessa data houve uma preocupação em preservar toda a documentação (J. Fontes, 2002). Assim, registos mostram que os priores e frades de Penafirme queixaram-se de um ataque de piratas em 1620 (J. Fontes, 2002), e novamente vários ataques entre 1648 e 1650 . Na tentativa de proteger o convento foi construído um forte no monte ao sul da praia do Porto Novo, sem resultados significativos. Assim, em 1662 (J. Fontes, 2002) foi mandado construir um novo convento situado nas atuais ruinas do convento (Ponto 8 da TABela II e na fig. 2, e ainda fig. 4a). Por outro lado, segundo J. Fontes (2002) a guarnição do forte do Porto Novo salvou-se pelo que teráo sido muito provavelmente estas as testemunhas que relataram o tsunami no Porto Novo. O forte foi totalmente destruído pelo tsunami e em 1910 ainda havia alguns vestígios das muralhas (J. Fontes, 2002). As alturas das ondas do tsunami relatadas pelas testemunhas $(16-18 \mathrm{~m})$ foram muito possivelmente estimadas grosseiramente pela altura a que as peças de artilharia ficaram nas rochas. O trabalho de campo demonstra que o monte ao sul da praia do Porto Novo (Ponto 3) está a cerca de $17 \mathrm{~m}$ de altura, o que efetivamente valida os relatos. Por outro lado, vários documentos (J. Fontes, 2002) indicam que na altura do sismo, o antigo convento já estava abandonado e que um novo estava em fase de construção. Este facto demonstra que não havia nenhum religioso no convento e portanto, as únicas testemunhas no porto novo seriam os guardas do forte. No entanto, o novo convento foi totalmente destruído pelo sismo e só a partir de 1758 é que este começou a ser reconstruido na sua atual localização (Ponto 11, e fig. 4b), e a partir de 1764 é que houve a transferência definitiva dos religiosos de Penafime para o novo convento (J. Fontes, 2002). Adicionalmente, dada a proximidade da Póvoa de Penafirme (Ponto 10) à costa, teria sido possível que os seus habitantes tivessem ido observar o mar, na zona da atual Praia de Santa Cruz (Ponto 9).

Os relatos históricos descrevem ainda o surgimento de depósitos de areia branca e cinza bem como o surgimento de diversos olhos de água. Esta descrição tem levado a uma certa confusão entre os fenómenos associados ao sismo e os que são descriçôes do tsunami. Trabalhos de campo efetuados após sismos modernos demonstram que a liquefação e abertura de fissuras no solo são fenómenos comuns associados a sismos, e que nada têm a ver com tsuna- 
$m i$, podendo ocorrer em regióes localizadas longe do mar. Por exemplo, após o sismo de 2003 no Japáo ocorreram diversos depósitos de areia branca em campos de arroz (fig. 5a). Por outro lado, após o sismo de 2011 também no Japão há registos do aparecimento de cinza preta (e.g. K. Wakamatsu, 2012) e abertura de fissuras com largura e profundidades significativas. No entanto, o que foi interessante no caso do sismo de 1755 foi o aparecimento de diversos "olhos de água", fenómeno que se refere a fontes termais, nome que ainda hoje se atribui à fonte dos Frades (Ponto 5 da Tabela II e fig. 5c).

A existência da Fonte Santa (Ponto 7 da Tabela II e localização na fig. 2) é conhecida desde séculos, no entanto os primeiros documentos referentes às suas propriedades terapêuticas datam de 1726 (J. Fontes, 2002): "junto ao Convento de Penafirme (...) se acha huma [sic] fonte, cuja agoa [sic] he [sic] remedio efficaz [sic] de dores nefriticas [sic], pela insigne virtude que tem de desfazer; e expulsar as pedras, e areas [sic] dos rins e bexiga". O nome de Fonte Santa (fig. 5d) deve-se à presença da rainha Isabel. Esta nasceu em 1269 ou 1270, e em 1282 casa com o rei Dinis de Portugal (M. F. Andrade, 2014). Em Portugal, recebe do seu esposo um conjunto de bens, em arras, bem como outras doaçóes que constituem um património que gere por meio dos seus oficiais cobradores de rendas e direitos na relação direta com os produtores (M.F. Andrade, 2011). Deste património faz parte Torres Vedras que, sabemos, a rainha visita por diversas vezes na companhia do seu esposo, para inaugurar um novo porto (na
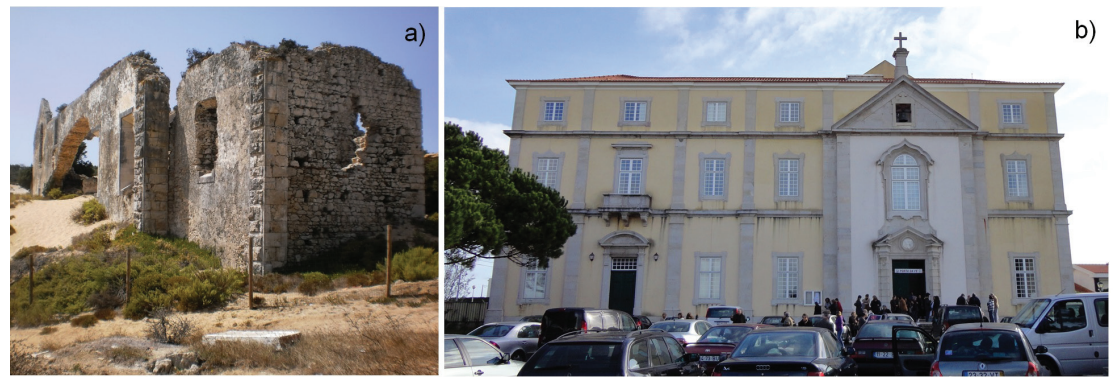

Fig. 4 - Convento de Penafirme: a) ruinas (Ponto 8 da Tabela II); b) Novo convento localizado na Póvoa de Penafirme (Ponto 11 da Tabela II).

Fig. 4 - The Penafirme convent: a) ruins (Point 8 of TABLE II); (b) new convent located at Povoa de Penafirme (Point 11 of TABLE II). 
praia do Porto Novo), ou para fazer as suas obras de misericórdia, ou ainda com o intuito de visitar as suas terras e conhecer melhor as suas gentes. A ela atribui o imaginário popular, como em muitos outros locais, intervençóes milagrosas que correspondem, com certeza, a uma presença mais ou menos constante da sua figura e das suas ação em prol das comunidades que protege e, neste caso, da torriense (J. Fontes, 2002). Apesar da frequente presença da rainha na zona, e de eventualmente ter passado pela fonte, aquando por exemplo da inauguração do porto, os documentos existentes não provam que era visitante regular da fonte, e muito provavelmente deve-se a crença popular. Porém, só durante os Séc. XIX e XX (e principalmente na década de 1950) foram realizados vários estudos no sentido de avaliar a situação viável comercial das termas (fig. 5b) bem como a realização de análises (p.ex.. H. Chaminé et al., 2004) para avaliar as suas propriedades. As atuais termas do Vimeiro caracterizam-se por terem duas fontes: i) Santa Isabel ou Águas Santas (Ponto 7B, e fig. 5d). Esta água é apenas utilizada para ingestáo devidamente prescrita por um médico termal. Na margem oposta do Rio Alcabrichel encontram-se piscinas abertas ao público apenas nos meses de verão (Ponto $7 \mathrm{a}$, e fig. 5 e); ii) A fonte dos Frades ou Olhos de Água.
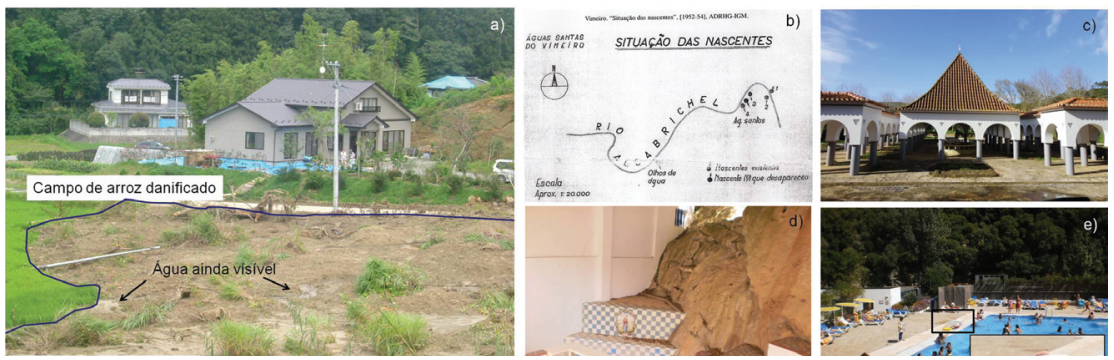

Fig. 5 - a) Liquefação ocorrida devido ao sismo de Miyagi, Japão a 27 julho 2003. Foto tirada pela primeira autora a 2 de Agosto de 2003; b) Representação esquemática da situação das nascentes do Vimeiro em 1952-54 (J. Magorrinha, 2000); c) Termas dos Frades ou "Ólhos de Água"; d) Termas do Vimeiro - Águas Santas; e) termas do Vimeiro - piscinas.

Fig. 5 - a) Liquefaction due to the July 27, 2003 Miyagi earthquake (Japan). Foto taken by the first author on August 2, 2003; b) Schematic representation the situation of the Vimeiro spring waters in 1952-54 (J. Magorrinha, 2000); c) Frades or "Ólhos de Água" spring waters; d) Vimeiro spring waters - Holy waters; e) Vimeiro spring waters - swimming pool. 


\section{Modelação numérica do tsunami}

\section{Condições do modelo}

O deslocamento inicial da superfície do mar foi calculado considerando os parâmetros da falha propostos por A. Santos et al. (2009), usando as fórmulas de Y. Okada (1985). O deslocamento inicial máximo é cerca de $6 \mathrm{~m}$, como mostra a fig. 6a. De modo a calcular as áreas inundadas pelo tsunami em Peniche e na Lourinhã, as equaçôes não lineares das águas pouco profundas foram discretizadas pelo esquema leap-frog (F. Imamaura, 1995). Sáo aplicadas a uma rede de 5 domínios. Cada domínio tem áreas cada vez mais pequenas, requerendo um refinamento do tamanho da grelha utilizada, como é demonstrado na fig. 6. O primeiro domínio é o de maior área e tem uma grelha de $2025 \mathrm{~m}$. Seguidamente, os domínios 2 e 3 têm grelhas de $675 \mathrm{~m}$ e $225 \mathrm{~m}$, respetivamente. Finalmente os domínios 4 e 5 tem grelhas de $75 \mathrm{~m}$ e $25 \mathrm{~m}$, e já incluem detalhes das zonas costeiras e topografia. $\mathrm{Na}$ construção dos vários domínios foram utilizadas cartas batimétricas (GEBCO, 2003, IH, 2011) e mapas topográficos (IGeoE, 2004, 2009).

O modelo numérico foi aplicado duas vezes, com diferenças apenas na topografia no domínio 5 (fig. 6e). Na primeira simulaçáo, para a validação histórica, foi utilizada a topografia histórica na vizinhança nas ruinas do convento de Penafirme cujo trabalho de campo demonstrou que o terreno estava pelo menos $2 \mathrm{~m}$ abaixo do nível atual (comparaçáo entre os Pontos 8A e 8B, da TABela II e fig. 4a). Na segunda simulaçáo, considerando um cenário da atualidade, foi considerada a topografia atual na vizinhança das praias de Porto Novo e Santa Rita (IgeoE, 2004, 2009). A evolução do assoreamento em Peniche demonstra que a topografia não variou significativamente desde o séc. XVIII; além disso, o centro histórico ainda existe, pelo que em ambos os cálculos foi considerada a topografia atual de Peniche no domínio 5. A batimetria também foi considerada a atual em ambos os cálculos. 


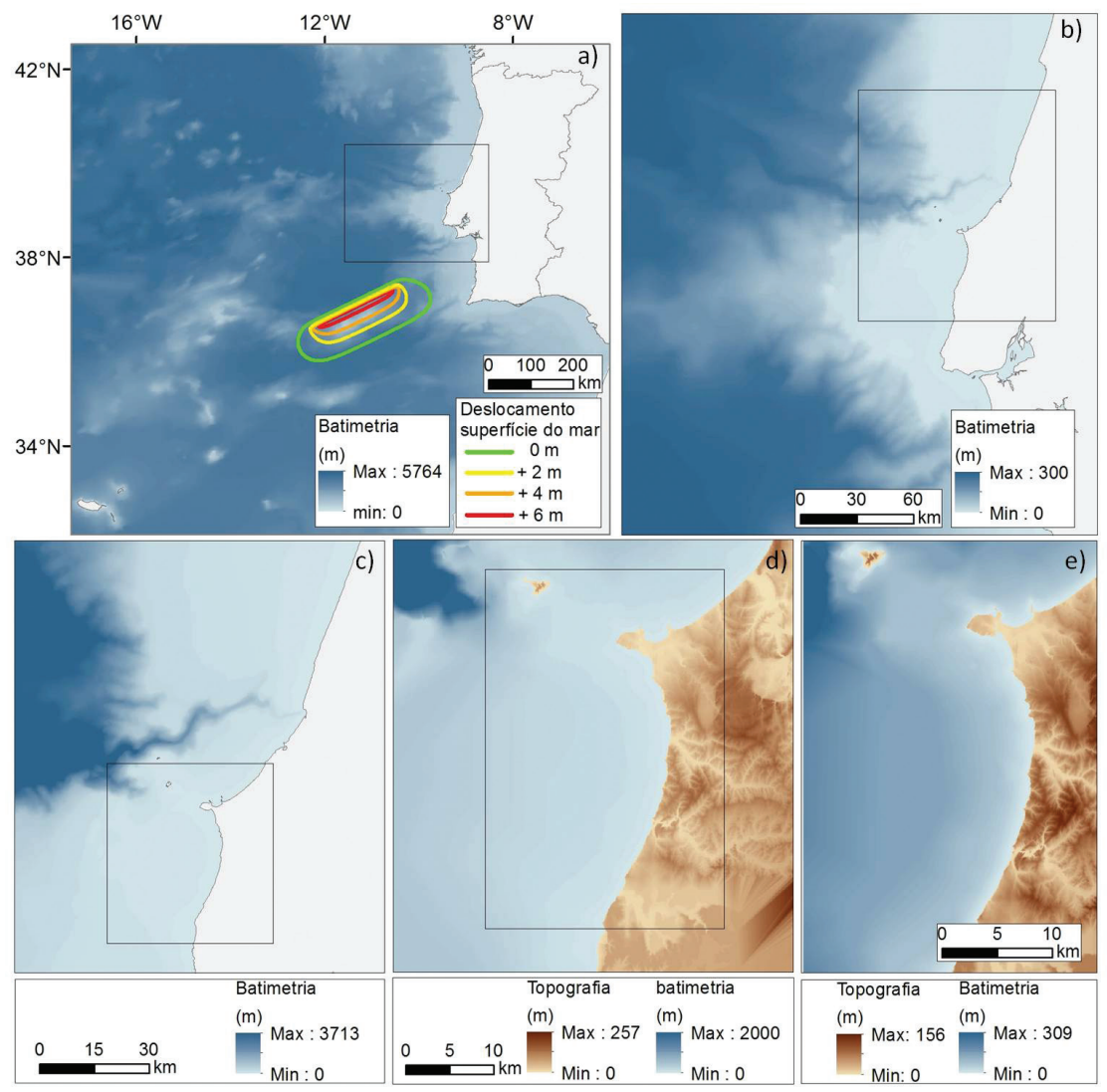

Fig. 6 - Condiçôes do modelo: a) deslocamento inicial da superfície do mar na região 1, com uma célula de $2025 \mathrm{~m}$; b) regiáo 2 com uma célula de $675 \mathrm{~m}$; c) região 3 com uma célula de $225 \mathrm{~m}$; d) regiáo 4 com uma célula de $75 \mathrm{~m}$; e) regiáo 5 com uma célula de $25 \mathrm{~m}$. Fig. 6 - Nesting conditions: a) initial sea surface displacement at region 1 with $2025 \mathrm{~m}$ cell size; b) region 2 with $675 m$ cell size; c) region 3 with $225 m$ cell size; d) region 4 with $75 \mathrm{~m}$ cell size; e) region 5 with $25 \mathrm{~m}$ cell size.

\section{Resultados da modelação numérica}

\section{Validação histórica}

A fig. 7 mostra os instantâneos da altura da água aos 50, 60, 70 e 75 minutos após o sismo. Na fig. 7a o tsunami aproxima-se da costa, amplificando 
significativamente a cerca de $2 \mathrm{~km}$ da costa. Por outro lado, aos 70 minutos (fig. 7c) a primeira onda retrocede sendo visível até cerca de $2 \mathrm{~km}$ da costa. Estes resultados estão de acordo com os relatos históricos, resumidos na TABela I. Por outro lado, o instantâneo calculado aos 75 minutos (fig. 7d) mostra que o tsunami aproxima-se de Maceira (Ponto 6) a cerca de 2,8 km da costa. Os habitantes de Maceira (Ponto 6) também sentiram o sismo e muito provavelmente podem ter visto o tsunami a subir o Rio Alcabrichel. Estes resultados provam que o tempo de percurso descrito pelas testemunhas está correto, apesar de não ser obtido ao longo da costa.

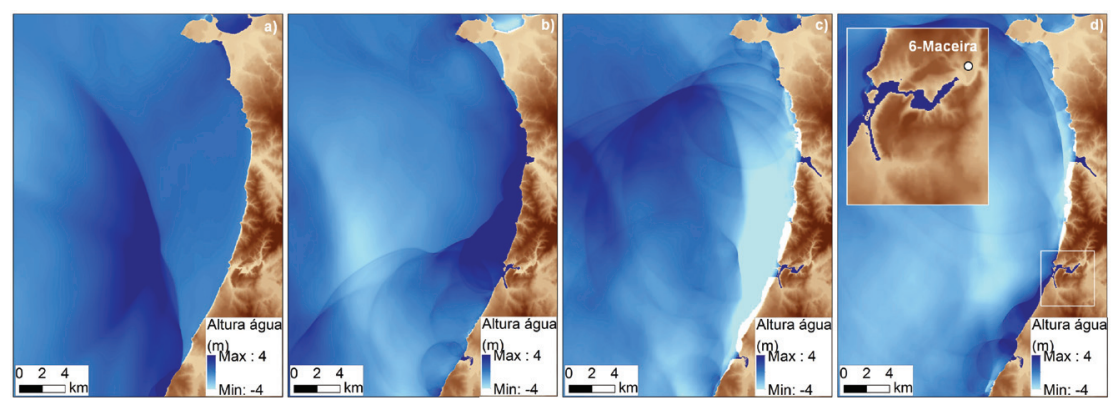

Fig. 7 - Instantâneos da altura da água do tsunami, em minutos após o sismo: a) 50; b) 60 ; c) 70 ; d) 75 .

Fig. 7 - Tsunami water level snapshots, in minutes after the earthquake: a) 50; b) 60; c) 70 ; d) 75 .

A altura de inundação nas ruinas do convento de Penafirme (Ponto 8) varia entre 4,7 - 4,9 m (fig. 8), o que é suficiente para causar danos significativos no edifício, confirmando assim os relatos históricos que indicam que o convento ficou inabitável. A variação da altura da água com o tempo no Porto Novo mostra que efetivamente houve uma amplificação local nas arribas chegando aos 10,9 m de altura. Por outro lado, a variação da altura da água com o tempo na Costa da Póvoa de Penafirme - Praia de Santa Cruz (Ponto 9) demonstra que ocorreram três ondas maiores que $4 \mathrm{~m}$ de altura, validando os relatos apresentados na TABela I. Deste modo demonstra-se que o modelo reproduz os relatos históricos, validando as condiçóes do modelo numérico bem como os parâmetros da fonte do tsunami. 

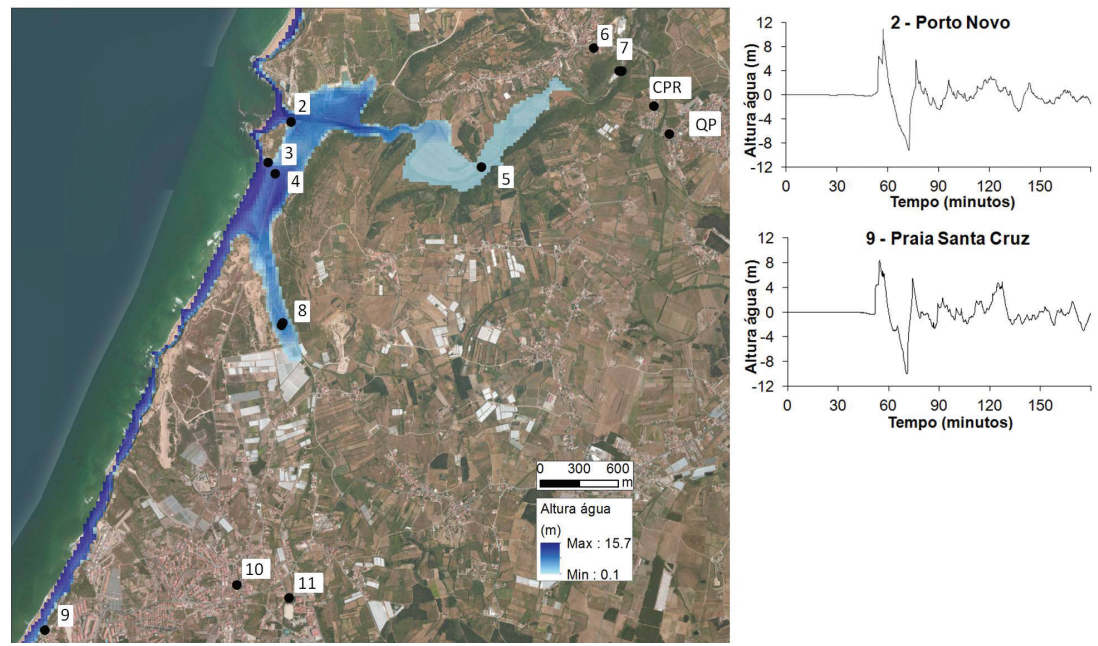

Fig. 8 - Resultados do modelo numérico para a validação histórica: altura da inundação na vizinhança da praia de Porto Novo, e variação da altura da água com o tempo no Porto Novo e na costa de Penafirme.

Fig. 8 - Numerical model results for historical validation: Inundation depth at the Porto Novo beach vicinity and water level waveforms at Porto Novo and at Penafirme coastline.

\section{Cenário na atualidade}

$\mathrm{Na}$ segunda simulação foi considerada a topografia atual. A fig. 9 mostra as áreas inundadas e a altura da água, variando entre 0,1 e 16,9 m, em que todas as praias de Peniche e da Lourinhã são totalmente inundadas. Em Peniche, as praias a norte são inundadas com alturas de água que variam de 0,1 m a 6,8 m. O porto de Peniche é inundado até à praia da Gamboa, numa distância horizontal de aproximadamente $1 \mathrm{~km}$, chegando às muralhas, com alturas que variam entre $0,2 \mathrm{~m}$ e $6,3 \mathrm{~m}$. A praia do Molhe Leste á bastante afetada pelo tsunami, com altura máxima de $8,95 \mathrm{~m}$, tendo de um modo geral alturas superiores a $2 \mathrm{~m}$. A praia do Medão/Supertubos tem alturas de inundação que variam entre $0,1 \mathrm{~m}$ e $5,95 \mathrm{~m}$. Na praia da Consolação a altura máxima chega aos 6,26 m. Na praia de S. Bernardino as alturas da água variam entre 0,99 $\mathrm{m}$ e $8,12 \mathrm{~m}$. A sul da praia de $\mathrm{S}$. Bernardino, mas ainda dentro dos limites do 
concelho de Peniche, obtém-se os valores máximos de inundação em todo o concelho, variando entre $10 \mathrm{~m}$ e $12,44 \mathrm{~m}$.

No município da Lourinhä, o tsunami inunda a praia da Areia Branca e penetra ao longo do vale do Rio Grande até cerca de 2,4 km para o interior. No entanto, a altura da água nos campos agrícolas é de um modo geral inferior a $2 \mathrm{~m}$. Na praia da Peralta verifica-se que a altura varia entre $0,1 \mathrm{~m}$ e $11,3 \mathrm{~m}$, enquanto na praia de Porto das Barcas a altura varia entre $0,1 \mathrm{~m}$ e $12,9 \mathrm{~m}$. $\mathrm{Na}$ praia de Porto Dinheiro verifica-se que a altura varia entre $0,1 \mathrm{~m}$ e $15 \mathrm{~m}$, enquanto na praia de Valmitão a altura varia entre $0,1 \mathrm{~m}$ e $16,9 \mathrm{~m}$, sendo este o máximo verificado em toda a área de estudo.

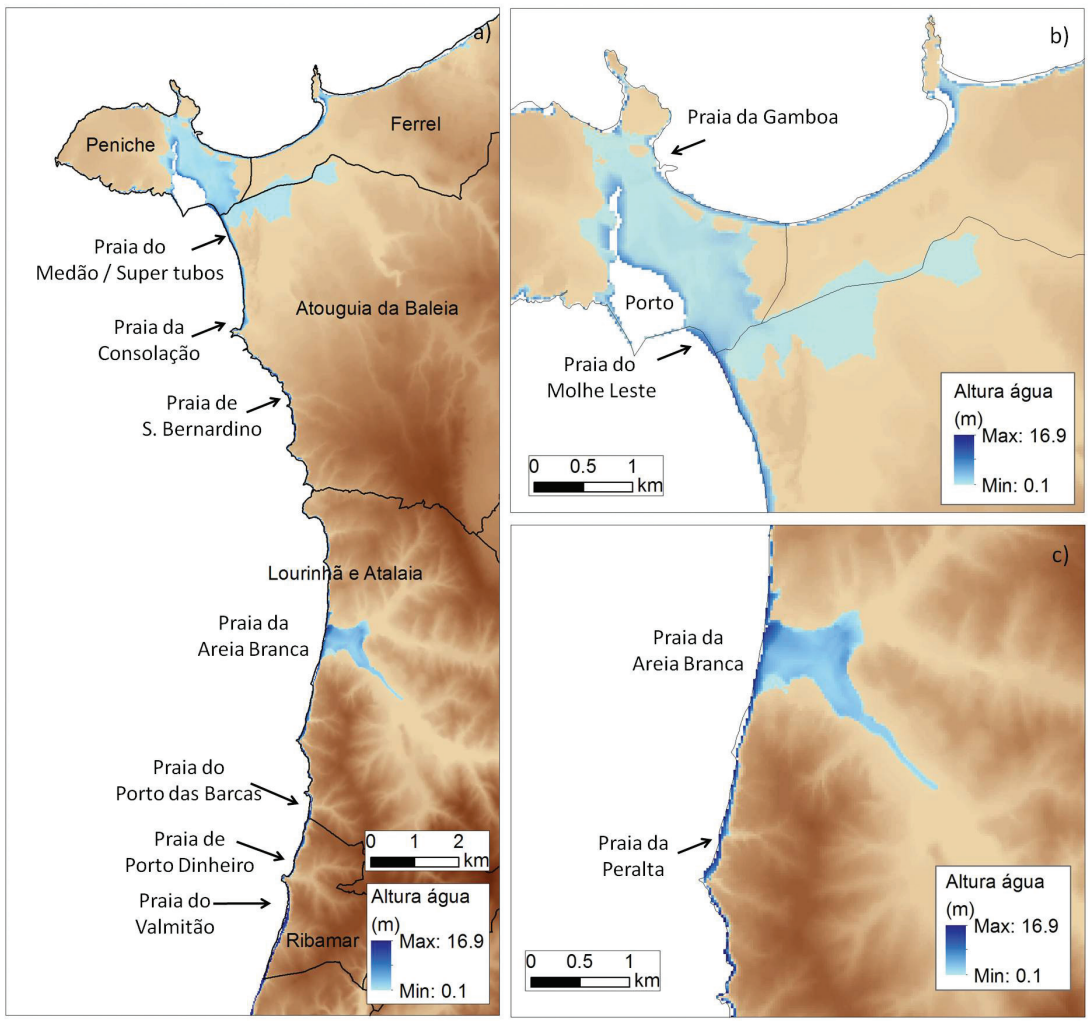

Fig. 9 - Altura da inundação.

Fig. 9-Inundation depth. 


\section{Avaliação do risco de tsunami}

\section{Perigosidade de tsunami}

De acordo com a matriz de Avaliaçáo da Perigosidade de Tsunami (A. Santos et al., 2011) é necessário ter em consideração a altura da água, combinada com o tempo de percurso da chegada da primeira onda de tsunami ao local em estudo, de modo a obter a perigosidade de tsunami (fig. 10). A classificação da perigosidade de tsunami varia entre reduzida e crítica.

A fig. 7 mostra que o tsunami demora cerca de 45 minutos a chegar ao município de Peniche, pelo que a suscetibilidade dos tempos de percurso do tsunami é moderada. Por outro lado, a suscetibilidade de inundação por tsunami

\begin{tabular}{|c|c|c|c|}
\hline $\begin{array}{l}\text { Altura da água } \\
\text { (metros) }\end{array}$ & Classificação & $\begin{array}{l}\text { Tempo de percurso } \\
\text { (minutos) }\end{array}$ & Classificação \\
\hline Até 2 & Reduzida & Até 20 & Crítica \\
\hline Até 5 & Moderada & Até 30 & Elevada \\
\hline Até 10 & Elevada - moderada & Até 40 & Elevada - moderada \\
\hline Até 15 & Elevada & Até 50 & Moderada \\
\hline Mais de 15.1 & Crítica & Mais de 50.1 & Reduzida \\
\hline
\end{tabular}

\begin{tabular}{|l|c|c|c|c|c|}
\hline & \multicolumn{4}{|c|}{ Perigosidade de Tsunami } \\
\hline Crítica & $\begin{array}{l}\text { Elevada }- \\
\text { moderada }\end{array}$ & Elevada & Elevada & Crítica & Crítica \\
\hline Elevada & $\begin{array}{l}\text { Elevada }- \\
\text { moderada }\end{array}$ & $\begin{array}{l}\text { Elevada }- \\
\text { moderada }\end{array}$ & Elevada & Elevada & Crítica \\
\hline Elevada - moderada & Moderada & $\begin{array}{l}\text { Elevada }- \\
\text { moderada }\end{array}$ & $\begin{array}{l}\text { Elevada - } \\
\text { moderada }\end{array}$ & Elevada & Elevada \\
\hline Moderada & Moderada & Moderada & $\begin{array}{l}\text { Elevada - } \\
\text { moderada }\end{array}$ & $\begin{array}{l}\text { Elevada - } \\
\text { moderada }\end{array}$ & Elevada \\
\hline Reduzida & Reduzida & Moderada & $\begin{array}{c}\text { Moderada } \\
\text { moderada }\end{array}$ & $\begin{array}{l}\text { Elevada }- \\
\text { moderada }\end{array}$ \\
\hline T. Percurso & Reduzida & Moderada & $\begin{array}{l}\text { Elevada - } \\
\text { moderada }\end{array}$ & Elevada & Crítica \\
\hline
\end{tabular}

Fig. 10 - Matriz de Perigosidade de Tsunami, considerando a altura da água e os tempos de percurso (Fonte: A. Santos et al., 2011).

Fig. 10 - Tsunami hazard matrix, by considering the water level height and travel times (Source: A. Santos et al., 2011). 
varia entre reduzida e elevada, sendo maioritariamente moderada em todas as praias e reduzida no porto e zonas circundantes, como mostra a fig. 11 .

De igual modo, a fig. 7 mostra que o tsunami demora cerca de 50 minutos a chegar ao município da Lourinhá, pelo que a suscetibilidade dos tempos de percurso é reduzida. Por outro lado, a suscetibilidade de inundação por tsunami varia entre reduzida a elevada na freguesia da união da Lourinhã e Atalaia, sendo maioritariamente elevada-moderada na praia da Peralta e elevada na praia de Porto das Barcas. A suscetibilidade de inundação por tsunami na freguesia de Ribamar varia entre reduzida a crítica, sendo esta a freguesia mais suscetível de todo o município (fig. 11).
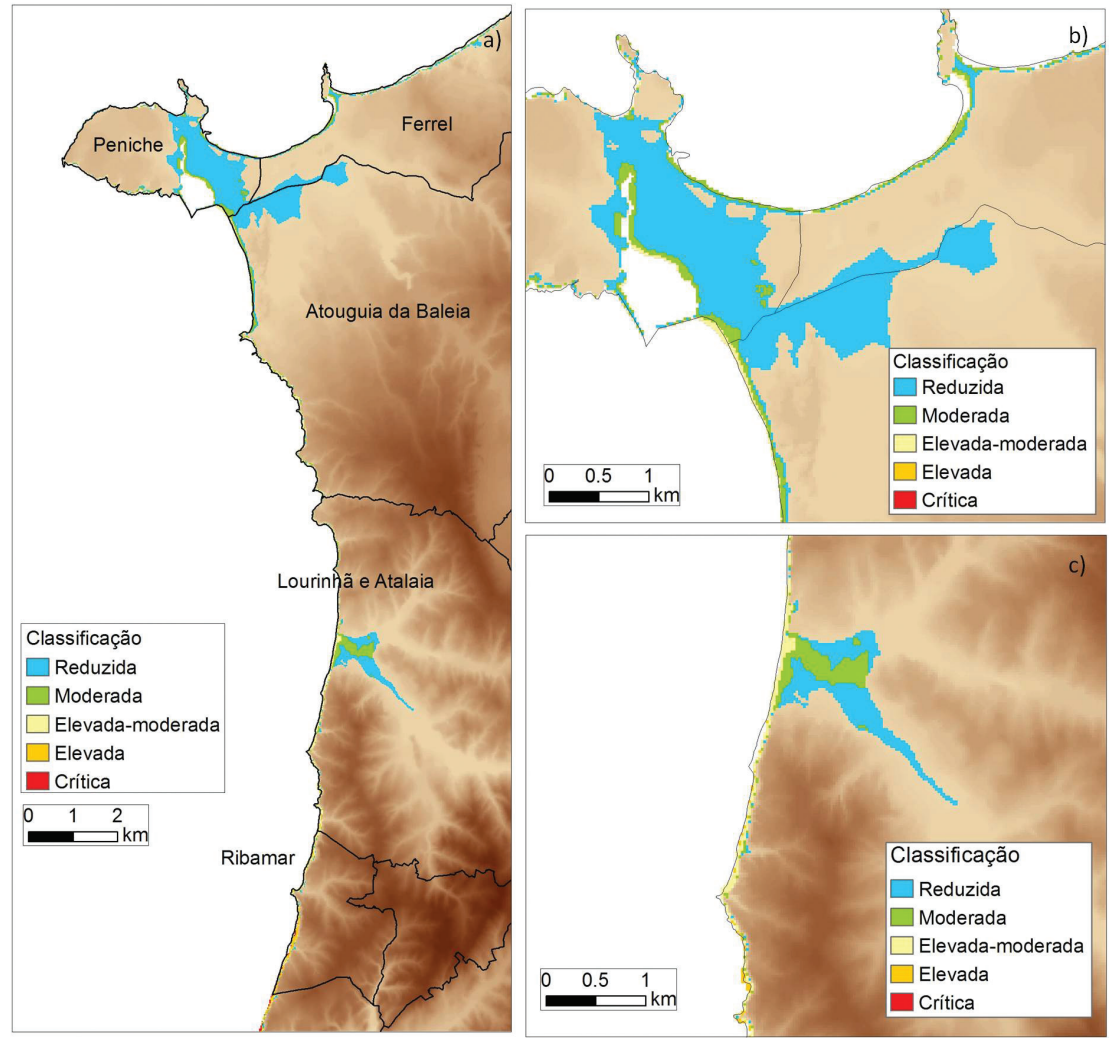

Fig. 11 - Susceptibilidade da altura da água.

Fig. 11 - Water level susceptibility. 
A perigosidade de tsunami resulta do cruzamento entre as alturas da água e os tempos de chegada. Assim, o município de Peniche tem duas classes de perigosidade: moderada e elevada-moderada (fig. 12). Praticamente em todo o concelho a perigosidade de inundação por tsunami é moderada, exceto nas praias do Molhe Leste e de S. Bernardino onde é elevada-moderada.

No município da Lourinhá a perigosidade de tsunami tem 3 classes de perigosidade: reduzida, moderada e elevada-moderada (fig. 12). A freguesia da Lourinhã e Atalaia tem perigosidade que varia entre reduzida e elevada-moderada (praia do Porto das Barcas). A perigosidade é moderada na praia da Peralta. Praticamente toda a costa da freguesia de Ribamar tem perigosidade elevada-moderada, sendo esta a freguesia mais afetada no concelho.
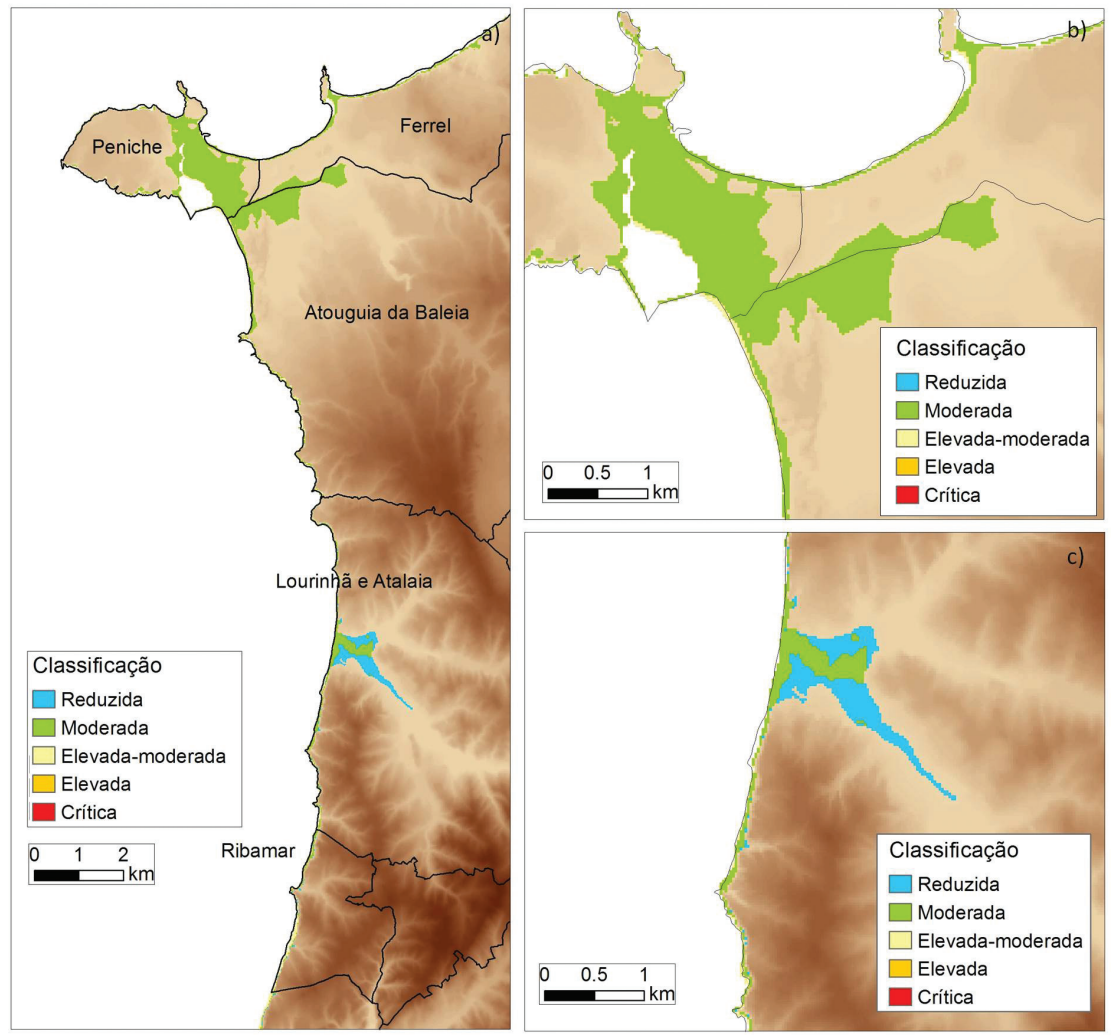

Fig. 12 - Classificação da perigosidade de tsunami.

Fig. 12 - Tsunami hazard classification. 


\section{Elementos expostos}

No município de Peniche há elementos estratégicos, vitais e sensíveis no apoio à emergência que se encontram em situação de perigosidade moderada, nomeadamente o quartel de bombeiros, polícia marítima, quatro escolas e dois hotéis, como mostra a TABELA III. É importante salientar que como a zona histórica é inundada, parte da freguesia de Peniche pode ficar isolada (fig. 13). Adicionalmente, encontram-se outros elementos em situação de perigosidade moderada: dois equipamentos desportivos, um ponto da rede PT, dois postos de abastecimento de combustíveis, o tribunal, o mercado municipal, o parque aquático, 262 pontos de recolha de resíduos sólidos e 31 ecopontos. Relativamente à exposição dos eixos rodoviários, há troços que são inundados: cerca de $1720 \mathrm{~m}$ do IP6; cerca de $1 \mathrm{~km}$ da estrada nacional n. ${ }^{\circ} 114$ e $590 \mathrm{~m}$ da estrada municipal n. ${ }^{\circ}$ 578. É ainda de salientar que 3124 edifícios são inundados pelo tsunami, dos quais três estão localizados na zona de perigosidade elevada-moderada. A população exposta foi estimada com base nas subsecçóes estatísticas afetadas pela área inundada do tsunami, recorrendo-se a dados dos Censos da população de 2011 (INE, 2011). A população presente estimada contabiliza 4671 pessoas enquanto os residentes são 4763 .

No município da Lourinhã há 68 edifícios afetados pela inundação por tsunami, sendo que 56 estáo na classe de perigosidade reduzida e 23 na classe de perigosidade moderada, como se mostra na TABela IV. Para além disso, 60 equipamentos para recolha de resíduos sólidos urbanos estão na zona inundada, onde 12 se localizam na zona de perigosidade moderada. Há furos de captação de água que se localizam em zona de perigosidade reduzida e há 4 estações elevatórias que são inundadas pelo tsunami. No entanto, há troços de vias que são afetados pelo tsunami: cerca de $1 \mathrm{~km}$ de estradas municipais, cerca de $300 \mathrm{~m}$ de estradas nacionais, cerca de 180 $\mathrm{m}$ de outras vias estruturais, e cerca de $1900 \mathrm{~m}$ de outras vias locais, os quais podem tornar alguns zonas isoladas (fig. 13). 
TABELA III - Elementos expostos no município de Peniche.

TABLE III - Exposed elements at Peniche municipality.

\begin{tabular}{|c|c|c|c|}
\hline \multirow[b]{2}{*}{ Elementos expostos } & \multicolumn{3}{|c|}{ Perigosidade de inundaçáo por tsunami } \\
\hline & Moderada & Elevada-moderada & Total \\
\hline Bombeiros & 1 & 0 & 1 \\
\hline Polícia Marítima & 1 & 0 & 0 \\
\hline Escolas & 4 & 0 & 4 \\
\hline Hotéis & 2 & 0 & 2 \\
\hline Equipamentos desportivos & 2 & 0 & 0 \\
\hline Rede pt & 1 & 0 & 1 \\
\hline Posto abast. combustíveis & 2 & 0 & 2 \\
\hline Tribunal & 1 & 0 & 0 \\
\hline Mercado municipal & 1 & 0 & 1 \\
\hline Parque aquático & 1 & 0 & 0 \\
\hline Resíduos sólidos & 262 & 2 & 264 \\
\hline Ecopontos & 31 & 0 & 31 \\
\hline Estrada Nacional & $1004 \mathrm{~m}$ & $0 \mathrm{~m}$ & $1004 \mathrm{~m}$ \\
\hline Estrada Municipal & $588 \mathrm{~m}$ & $0 \mathrm{~m}$ & $588 \mathrm{~m}$ \\
\hline IP6 & $1716 \mathrm{~m}$ & $0 \mathrm{~m}$ & $1716 \mathrm{~m}$ \\
\hline Edifícios & 3121 & 3 & 3124 \\
\hline População presente & --- & --- & 4671 \\
\hline População residente & --- & --- & 4763 \\
\hline
\end{tabular}

\section{Discussão}

Os relatos históricos do Tsunami de 1755 em Peniche são escassos, sendo no entanto possível identificar que a zona histórica está a cota inferior a $5 \mathrm{~m}$ e que não sofreu alterações significativas desde o séc. XVIII. Os sistemas dunares em geral, e concretamente o sistema dunar de Peniche, constituem por excelência uma proteção natural das terras emersas às recorrentes perigosidades naturais que afetam 

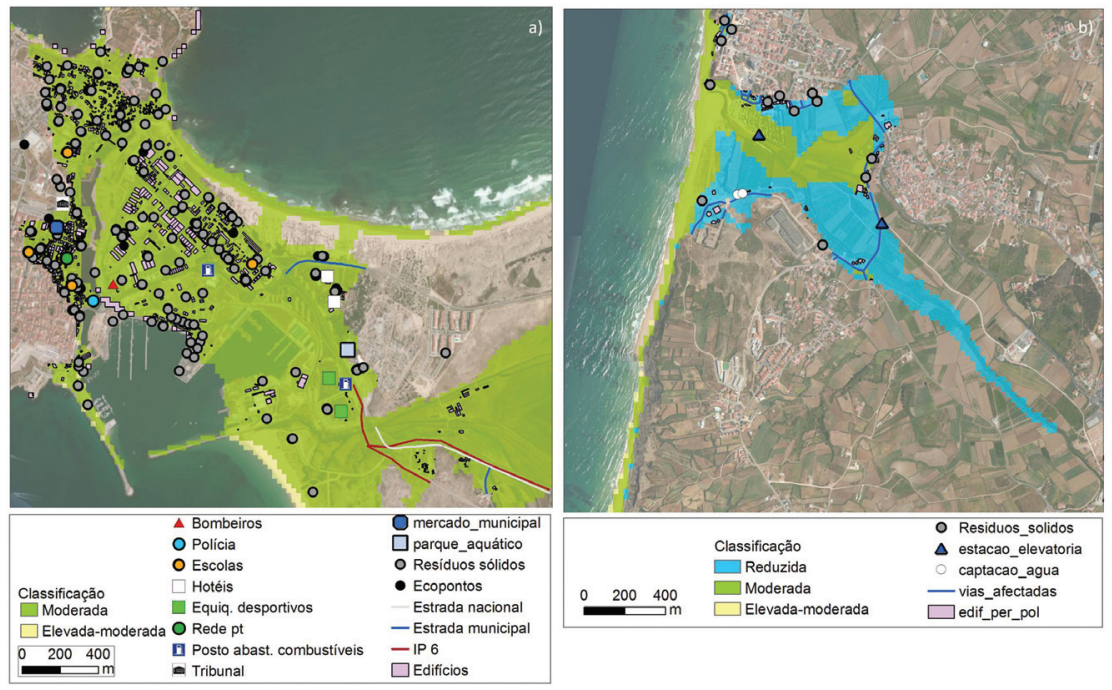

Fig. 13 - Elementos expostos nas áreas inundadas de Peniche (a) e Lourinhã (b).

Fig. 13 - Exposed elements on the inundated areas of Peniche (a) and Lourinhã (b).

TABELA IV- elementos expostos no município de Lourinhã.

TABLE IV - Exposed elements at Lourinhä municipality.

\begin{tabular}{|c|c|c|c|c|}
\hline \multirow[b]{2}{*}{ Elementos expostos } & \multicolumn{4}{|c|}{ Perigosidade de inundaçáo por tsunami } \\
\hline & reduzida & moderada & elevada-moderada & Total \\
\hline Resíduos sólidos & 48 & 12 & 0 & 60 \\
\hline Captação água (furo) & 2 & 0 & 0 & 2 \\
\hline Estação elevatória & 2 & 2 & 0 & 4 \\
\hline Estrada Municipal & $608 \mathrm{~m}$ & $347 \mathrm{~m}$ & 0 & $956 \mathrm{~m}$ \\
\hline Estrada Nacional & $280 \mathrm{~m}$ & $24 \mathrm{~m}$ & 0 & $304 \mathrm{~m}$ \\
\hline Outras Vias Estruturais & $0 \mathrm{~m}$ & $109 \mathrm{~m}$ & $74 \mathrm{~m}$ & $184 \mathrm{~m}$ \\
\hline Outras Vias locais & $1408 \mathrm{~m}$ & $463 \mathrm{~m}$ & $37 \mathrm{~m}$ & $1909 \mathrm{~m}$ \\
\hline Edifícios & 45 & 23 & 0 & 68 \\
\hline Populaçáo presente & --- & -- & --- & 928 \\
\hline População residente & --- & --- & --- & 956 \\
\hline
\end{tabular}


o litoral, como sejam a erosão marinha, os galgamentos oceânicos, as inundaçôes costeiras, as tempestades, o storm surge e os tsunami, funçáo particularmente relevante no contexto do risco de tsunami, fenómeno erosivo menos frequente mas de maior severidade, uma vez que os sistemas dunares constituem muitas vezes o único obstáculo entre o oceano e as populaçôes, bens e infraestruturas em espaço litoral. Assim, é aceitável assumir que aquando do Tsunami de Lisboa de 1755 as dunas tenham protegido o território do município de Peniche, afetando apenas as zonas baixas e desprotegidas da zona histórica. Por outro lado, os relatos na freguesia de A-dos-Cunhados são muito completos, tendo sido validados por trabalho de campo e modelação numérica do tsunami. Assim, foi possível confirmar: i) o tempo de percurso do tsunami até à Maceira (cerca de $3 \mathrm{~km}$ da costa) é de 75 minutos; ii) ocorreram três ondas na praia de Santa Cruz (na zona costeira da Póvoa de Penafirme); iii) o tsunami amplificou significativamente nas arribas da praia do Porto Novo, chegando aos $11 \mathrm{~m}$ de altura; iv) as alturas de inundaçấo nas ruinas do convento de Penafirme foram entre 4,7 -4,9 m, demonstrando que seria suficiente para o tornar inabitável; v) trabalho de campo efetuado após a ocorrência de sismos modernos demonstra que a liquefação do solo pode ocorrer, provocando depósitos de areia branca ou cinza, mesmo em zonas localizadas afastadas do mar, e que nada têm a ver com a inundação de tsunami. $\mathrm{O}$ modelo numérico demonstra que num cenário de ocorrência de um tsunami com magnitude equivalente ao Tsunami de Lisboa de 1755, a área sul do sistema dunar de Peniche será potencialmente mais afetada que a área norte. Tal circunstância deve-se fundamentalmente à combinação de alturas de inundação mais elevadas (até $8,95 \mathrm{~m}$ na praia do Molhe) e com o facto de as dunas a sul possuírem altura mais modesta, entre 7-8 m, e ainda à presença dos vales fluviais dos rios de Ferrel e São Domingos (com foz neste troço litoral), facilitando a penetração da água do oceano. Por sua vez, a altura de inundação a norte é mais modesta (até 6,8 $\mathrm{m})$ e as dunas a norte possuem maior altitude, entre 5-15 m. Adicionalmente, o troço ocidental do sistema dunar apresenta-se artificialmente estabilizado (com construçáo de duna artificial e enrocamento da sua base, medidas de proteçáo do litoral realizadas nas décadas de 1980-90) (R.Paixão, 2011), constituindo um obstáculo mais resistente à inundação das ondas de tsunami. 
Em praticamente todo o concelho de Peniche a perigosidade de inundação por tsunami é moderada, exceto nas praias do Molhe Leste e de S. Bernardino onde a perigosidade é elevada-moderada. Por outro lado, no município da Lourinhã a perigosidade de tsunami reparte-se por três classes: reduzida, moderada e elevada-moderada. A freguesia da Lourinhã e Atalaia tem perigosidade que varia entre reduzida e elevada-moderada (praia do Porto das Barcas). A perigosidade é moderada na praia da Peralta. Praticamente toda a costa da freguesia de Ribamar tem perigosidade elevada-moderada, sendo esta a freguesia mais afetada no concelho.

Os elementos expostos no município de Peniche incluem alguns elementos vitais à emergência que podem ficar inoperacionais, nomeadamente os bombeiros e a polícia marítima. Existem ainda 4671 pessoas expostas e 3124 edifícios potencialmente inundados, enquanto na Lourinhã há 956 residentes em risco, e 68 edifícios que podem ser inundados.

\section{Conclusão}

Apesar do porto de Peniche estar protegido por dois quebra-mares, os resultados deste estudo confirmam que o impacto de um tsunami semelhante ao de 1755 teria sérias consequências. Por outro lado, as praias do município da Lourinhã localizam-se nas proximidades de locais elevados o que permite aos utilizadores da praia evacuarem rapidamente para local alto em segurança. A exceção é a praia da Areia Branca. Por estas razóes é recomendado que estudos de avaliaçáo e gestão do risco de tsunami continuem, nomeadamente: i) atualização do modelo de inundação passando de um espaçamento de grelha final de $25 \mathrm{~m}$ para pelo menos $10 \mathrm{~m}$, o que implica uma re-avaliação dos elementos expostos; ii) análise comparativa entre a população residente e presente; iii) implantação de painéis informativos acerca do risco de tsunami nas praias e no porto de Peniche; iv) assinalar as zonas altas de refúgio, complementada com indicação dos caminhos a percorrer; v) testar estes percursos através de exercícios de evacuaçáo; vi) elevação da altura do quebra-mar do porto de Peniche em pelo menos $0,5 \mathrm{~m}$; vii) ordenamento e gestão sustentável das dunas. 


\section{Agradecimentos}

Os autores gostariam de agradecer ao Padre Eduardo Coelho da igreja de A-dos-Cunhados por ter tido a gentileza de permitir a consulta dos arquivos. Este artigo foi suportado pelo Projecto TsuRiMa - Gestáo do risco de tsunamis para o ordenamento do território e a protecçáo civil, Projeto PTDC/CSGEO/118992/2010, Fundação para a Ciência e Tecnologia (FCT).

\section{Bibliografia}

Andrade, M. F. (2014) Isabel de Aragão. Rainha Santa, Mãe exemplar, Lisboa, Temas e Debates.

Andrade, M. F. (2014) In oboedientia, sine proprio, et in castitate, sub clausura. A Ordem de Santa Clara em Portugal (séculos XIII e XIV), Tese de doutoramento apresentada à FCSH da Universidade Nova de Lisboa, 2011.

Blot M .L. P. (2003). Os portos na origem dos centros urbanos. Contributo para a arqueologia das cidades marítimas e fluvio-marítimas em Portugal. Trabalhos de Arqueologia, no ${ }^{\circ} .28$, Instituto Português de Arqueologia, Lisboa, 338 p.

Camilo, J. (1998). A regiāo de Maceira e o Terramoto de 1 de Novembro de 1755. Jornal Badaladas, Suplemento Freguesias - Maceira, n. ${ }^{\circ}$ 6, p. 6-7.

Chaminé, H. I., Fonseca, P. E., Carvalho, J. M., Azevedo, M., Gomes, A. e Teixeira, J. (2004). Geometria, cinemática e dinâmica diapírica da morfoestrutura do Vimeiro (Torres Vedras, Portugal central): implicaçóes para um modelo hidrogeológico Caderno Lab. Xeolóxico de Laxe Coruña, Vol. 29, p. 9-30.

Dias J. A. (2009). Alguns exemplos da rápida evolução costeira em Portugal. VII Reuniāo do Quaternário Ibérico, 5-9 Outubro 2009, Faro, p.17-21.

Fialho, J. (1910). Algumas notas curiosas - reprodução dos relatos do Padre António Duarte sobre o Tsunami de 1755, 24 de Maio de 1756, Arquivos da Igreja de A-dos-Cunhados.

Fontes, J. (2002). A dos Cunhados - itinerários da Memória, 575 p.

França J. C., Zbyszewski G., Moitinho de Almeida F. (1960). Notícia Explicativa da folha 26-C da Carta Geológica de Portugal 1:50 000. Serviços Geológicos de Portugal, Lisboa, 33 p.

GEBCO Digital Atlas. (2003). General Bathymetric chart of the Oceans, British Oceanographic Data Centre.

IGeoE - Instituto Geográfico do Exército (2004). Folhas 325AB, 326, 337, 338, 349, 350, 361, 362.

IGeoE - Instituto Geográfico do Exército (2009). Folhas 374, 375.

IH - Instituto Hidrográfico (2011). Carta da Série Internacional Oceano Atlântico Norte (CSIOAN) 24202, 24203.

Imamura F. (1995). Review of tsunami simulation with a finite difference method. Long-Wave runup models, World Scientific, 1995, 25-42. 
INE (2011). Censos de Portugal de 2011. http://www.ine.pt.

Koshimura, S., Oie, T., Yanagisawa, H., e Imamura, F. (2009). Developing fragility functions for tsunami damage estimation using numerical model and post-tsunami data from Banda Aceh, Indonesia. Coastal Engineering Journal, 51, 3:243-273.

Mangorrinha, J. (2000). O Lugar das Termas. Património e desenvolvimento regional. As estâncias termais da regiấo Oeste. Livros Horizonte, 302 pages.

Okada Y. (1985). Surface Deformation due to Shear and Tensile Faults in a Half Space. Bull. Seismol. Soc. Am., 75,4:1135-1154.

Oliveira, A. (1985). "Pesos e Medidas", in SERRÁO, Joel, Dicionário de História de Portugal, 5 , Porto, Livraria Figueirinhas, 67-72.

Paixão, R. (2013). Caracterização morfo-ecológica do sistema dunar de Peniche-Baleal (Costa Ocidental Portuguesa). Finisterra, XLVIII (95): 41-60.

Paixão, R. (2011). Avaliação da vulnerabilidade biofísica do sistema dunar de Peniche-Baleal. Dissertação de Mestrado em Geografia Física e Ordenamento do Território, Universidade de Lisboa, Lisboa, 137 p.

Santos, A., Fonseca, N., Pereira, S., Zezere, J. L., e Koshimura, S. (2012). Tsunami risk assessment at Figueira da Foz, Portugal, 15WCEE, September 24-28, Lisbon, Pages 10, paper No. 1931. http://riskam.ul.pt/images/pdf/paper_1931.pdf

Santos, A., e Koshimura, S. (2015) The Historical Review of the 1755 Lisbon Tsunami, Journal of Geodesy and Geomatics Engineering, 1, 38-52. Doi: 10.17265/2332-8223/2015.04.004.

http://www.davidpublisher.com/Public/uploads/Contribute/5538548886a24.pdf

Santos, A., Koshimura, S., e Imamura, F. (2009). The 1755 Lisbon Tsunami: Tsunami source determination and its validation. Journal Disaster Research, 4, 1:41-52.

Santos, A., Tavares, A. O., e Emidio, A. (2014). Comparative tsunami vulnerability assessment of an urban area: An analysis of Setúbal city, Portugal, Applied Geography, nº. 55, 19-29.

http://dx.doi.org/10.1016/j.apgeog.2014.08.009

Santos, A., Zezere, J. L., e Agostinho, R. (2011). The 1755 tsunami and the tsunami hazard assessment in Portugal mainland. VIII CGP, October 26. Lisbon. Pages 6. http://riskam.ul.pt/ images/pdf/Risco_68-375-1.pdf.

Sousa, L. (1928). O terramoto do 1. de Novembro de 1755 em Portugal e um estudo demográfico. Serviços Geológicos, n. ${ }^{\circ}$ 3, p. 479-949.

Wakamatsu, K. (2012). Recurrence of Liquefaction at the Same Site Induced by the 2011 Great East Japan Earthquake Compared with Previous Earthquakes, 15WCEE, September 24-28, Lisbon, Pages 10, paper No. 4572. 